\title{
EDITORIAL
}

\section{Emergency Radiology: what is different in children?}

\author{
Ron Zagoria ${ }^{1}$
}

Published online: 4 September 2015

(C) American Society of Emergency Radiology 2015

With this supplemental issue of Emergency Radiology, we complete the publication of this wonderful radiology series written by a leading authority in pediatric emergency radiology, Dr. Leonard Swischuk. Dr. Swischuk has shared his unique expertise and experience in the field of pediatric musculoskeletal radiology with our subscribers since 2007 with a feature article in every issue of Emergency Radiology. His articles have highlighted the often subtle findings of significant injuries hidden in radiologic studies of children. The findings are quite unique and substantially different from those that most of us are familiar with in adult radiologic examinations. His articles have been both enlightening and entertaining. While easy to read, each article has been packed with pertinent material to improve interpretation of pediatric examinations. He further emphasized the "key" points in each article with a short summary list at the end of the article. Together, these components have created a great series.

As Editor-in-Chief of Emergency Radiology and on behalf of our Editorial Board and the American Society of Emergency Radiology, I congratulate and thank Dr. Swischuk for contributing his skills to produce this superb article series.

Conflict of interest The author declares that he has no conflict of interest.
Ron Zagoria

Ron.Zagoria@ucsf.edu

1 Department of Radiology and Biomedical Imaging, University of California, San Francisco, San Francisco, CA, USA 